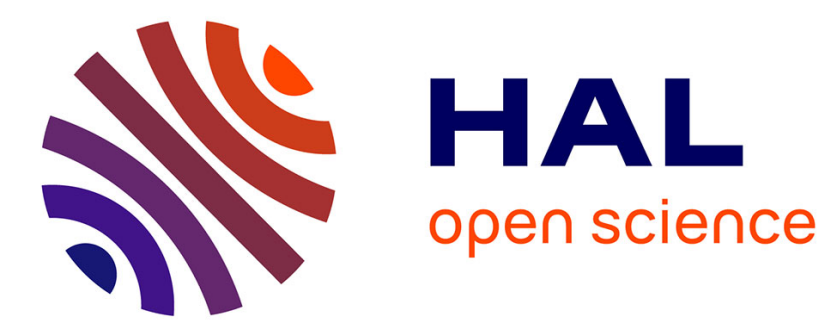

\title{
The CoVis Project: Building a Large-Scale Science Education Testbed
}

\author{
Louis M. Gomez, Barry J. Fishman, Roy D. Pea
}

\section{To cite this version:}

Louis M. Gomez, Barry J. Fishman, Roy D. Pea. The CoVis Project: Building a Large-Scale Science Education Testbed. Interactive Learning Environments, 1998, 6(1-2), pp.59-92. hal-00190604

\section{HAL Id: hal-00190604 https://telearn.archives-ouvertes.fr/hal-00190604}

Submitted on 23 Nov 2007

HAL is a multi-disciplinary open access archive for the deposit and dissemination of scientific research documents, whether they are published or not. The documents may come from teaching and research institutions in France or abroad, or from public or private research centers.
L'archive ouverte pluridisciplinaire HAL, est destinée au dépôt et à la diffusion de documents scientifiques de niveau recherche, publiés ou non, émanant des établissements d'enseignement et de recherche français ou étrangers, des laboratoires publics ou privés. 


\title{
The CoVis Project: Building a Large-Scale Science Education Testbed*
}

\author{
Louis M. Gomez \\ Northwestem Liniversity \\ Barry J. Fishman \\ University of Michigan \\ Roy D. Pea \\ SRI International
}

\begin{abstract}
This paper describes the construction and research program of the Learning Through Collaborative Visualization (CoVis) Project. a testbed for exploring science education reform with telecommunications technology. The CoVis testbed is contrasted with other forms of educational research in an "ecology of paradigms." which argues that testbeds are in fact a new serting for reseurch with different requirements and challenges for the researcher. Two extended examples of telecommunications research are provided as examples of the hind of research that testbeds are well suted to explore. The first example is the evolution of videoconferencing in the Covis testbed. The second example is the design and development of a networked groupware application called the Collaboratory Notebook.
\end{abstract}

:The authors gratefully acknowledge the support of the National Science Foundation through grants RED-9+5+729 and MDR-9253462. and the Illinois State Board of Higher Education. under the Eisenhower Program.

The authors would also like to thank the students and teachers of the CoVis project for their support and participation in this work. and give special acknowledgment to the members of the CoVis research team (Daniel Edelson. Eileen Lento, Laura D'Amico. Douglas Gordin. Samuel Kwon. Steven McGee. Kevin O'Neill. Gregory Shrader, and Raul Zaritsky) for their many contributions to the work described. and to the teachers and students. without whom none of this work would have been possible. In addition. the CoVis project would not have been possible without the contribution of individuals from Ameritech. Bellcore. the Exploratorium. the University of Illinois. Urbana-Champaign, and TERC. Special thanks to Elliot Soloway, University of Michigan. for early contributions as collaborator and in project conception and software design. Thanks to Nathan Bos. Chris Dede, Ann Holum. Joe Krajcik. and James Spillane for comments on an earlier draft of this paper.

All authors were located at Northwestern Liniversity when this work was started.

Correspondence: Barry J. Fishman. 610 E. University. 1228D. School of Education. University of Michigan. Ann Arbor, MI 48109-1259. USA. Tel. 734-647-9572. 


\section{INTRODUCTION}

Distributed learning environments using advanced computing and communications technology hold substantial promise for improving science education learning environments. The implementation and sustained use of such technologies on a large-scale basis in $\mathrm{K}-12$ school communities is a challenging design problem, due to the complexities of socio-technical systems. We describe a contribution to the problem's solution through an analysis of our experience in designing and implementing a constructivist-oriented, technology-intensive testbed used by a community of schools.

The Learning Through Collaborative Visualization (CoVis) project is a testbed for learning and technology composed of teachers. scientists, museum staff, industry personnel. and researchers working in concert to reform science education in middle- and high-school classrooms. Since its inception in 1992. the CoVis project has involved over 100 teachers and over 3.000 students using telecommunications as a critical leveraging technology to develop, and evolve through use, a wide array of new resources for learning. This testbed is now creating multiple opportunities for learners to engage in open-ended inquiry and new kinds of learning relationships. In essence, the CoVis project has established a community of invention that has spent the past six years constructing. experiencing. and evolving new kinds of science learning environments. In this paper we concentrate on the role of telecommunications technology in the CoVis project, and try to characterize some of the properties of what we have come to call "testbed research," in comparison to other forms of inquiry in research in interactive learning environments.

Telecommunications technologies have been fundamental to CoVis research and development. As a category, they have consumed considerable design, curricular, and monetary resources. We will describe in detail the various roles that telecommunications have played for the project's constituents and how our thinking about the utility of telecommunications has evolved throughout our testbed experience.

We focus here on testbeds because they are an important component in the development of an understanding of broad-based school reform. As we will describe, testbeds provide a research context that is more complex and informative than the "isolated islands of innovation" often associated with the study of exemplary teachers in schools with special resources. Because of their added complexity, testbeds contribute to knowledge about the transformation of entire large and complex school systems. 

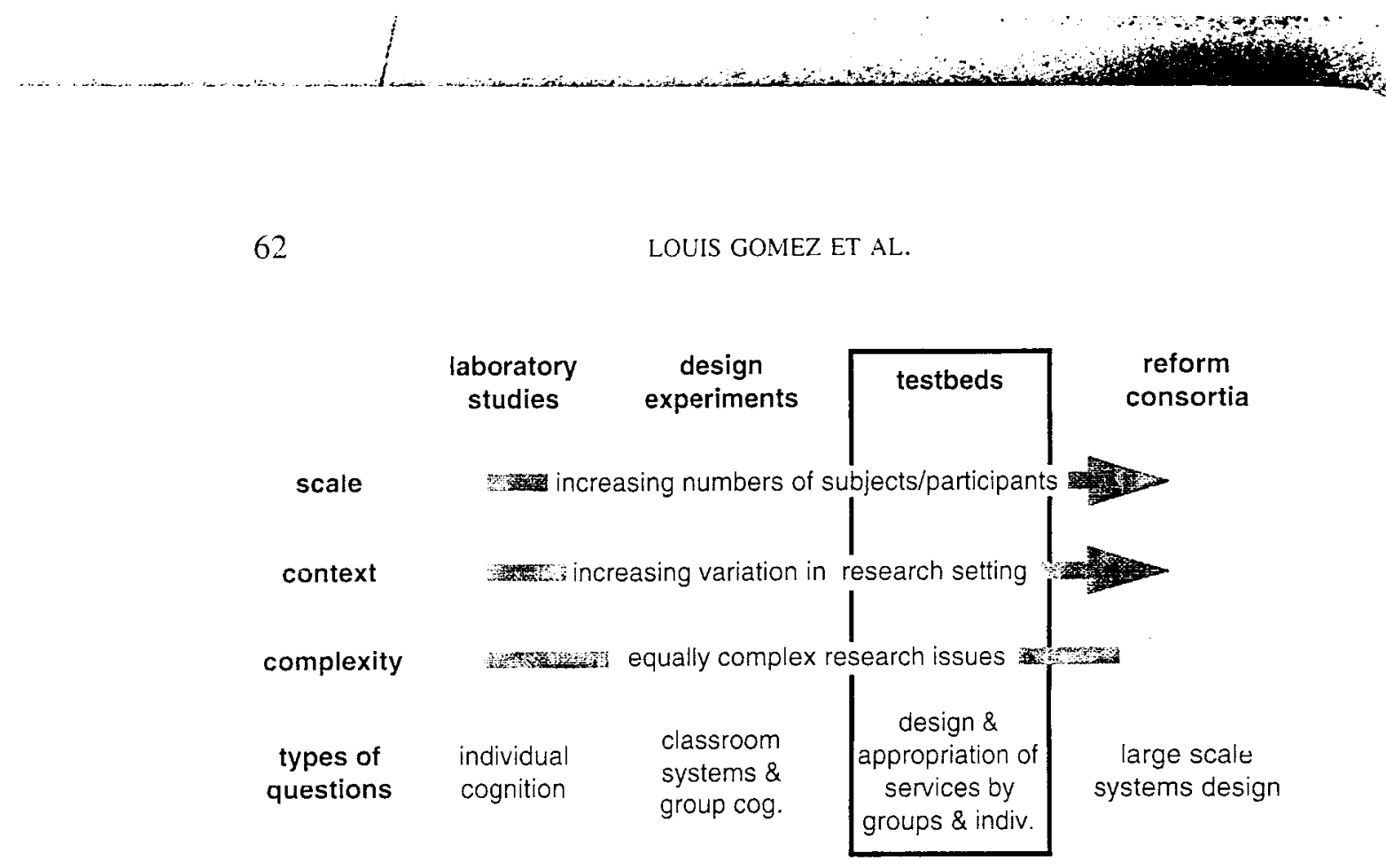

Fig. 1. Attributes of four educational research paradigms.

teaching and learning situated in diverse educational settings. The four types of investigative contexts exemplify points along continuums of scale, context. and complexity, and each is well suited to answering different types of research questions.

\section{Laboratory Studies}

Laboratory studies of learning and performance are the most well established of the paradigms in cognitive science studies of learning and teaching, and educational research. This type of research is designed to carefully control the research environment in order to determine correlations and. on occasion, to infer causal relationships between independent and dependent variables. The independent variable is often a stand-in for some aspect of cognitive structure or an aspect of the learning environment, such as the familiarity of the to-belearned material or the method of structuring the to-be-learned material. The dependent measure is often a measurable aspect of individual performance like the amount or type of information a learner can report after experience with the independent variable. The research is commonly conducted in a laboratory setting, as in most research on intelligent tutoring systems (e.g., Corbett et al.. 1990; Reiser et al.. 1992). or it may be conducted in classroom settings, as is often the case with studies of the effectiveness of new curriculum innovations. such as the introduction of intelligent tutors into mathematics classrooms (e.g.. Anderson et al.. 1995: Koedinger et al., 1995). Large numbers of such studies 
may also be aggregated, and effect sizes of instructional interventions determined in meta-analyses (e.g.. Kulik \& Kulik. 1989).

This type of research design often employs pre- and post-measures of change, and a comparison to some type of control group. In order to determine the impact of "interventions" or "treatments" (by analogy to clinical trials of pharmaceuticals) on cognitive structures and processes, extensive efforts are made to control for environmental factors that may introduce uncontrolled variation into the evaluation. Relatively small sample sizes are often necessary. Laboratory studies have proven extremely valuable in cognitive science for their capacity to address issues of individual cognition. For education, the key strength of laboratory studies of learning is addressing in depth the effects of one or a few aspects of an intervention. as it relates to cognitive theory or. in some cases, instructional design.

\section{Design Experiments}

A form of educational research that has emerged in the past decade is the design experiment (Brown. 1992; Collins, 1996). Design experiments can be characterized as efforts to "engineer" single class periods or entire classroom environments. Use of the term "engineer" is deliberate. as the process has been compared to that of the aeronautical engineer or artificial intelligence researcher who needs to devise new ways of thinking about the world in order to make progress. Brown describes her role as a researcher in this mode as "orchestrating all aspects of a period of daily life in classrooms" while "simultaneously conducting experimental studies of those innovations" (Brown, 1992. p. 141). It is frequently the case that important research questions emerge during the process of conducting such activities that could not have been anticipated prior to commencing the work. In such an environment, it is not possible to control the myriad factors that influence the daily lives of students and teachers. Instead, the research becomes a study of the systems that comprise classroom practice. Research programs such as the Community of Learners project (Brown \& Campione. 1990) have contributed to our understanding of issues of group cognition and learning in classroom systems.

Design as a style for research in teaching and learning has recently gained prominence for at least three reasons. First, there is renewed interest in "education" as a problem area that demands practical solutions. This perspective stands in sharp contrast to a view of schools as "research sites," with a different population of research subjects. The design focus places greater emphasis on finding solutions that work and relatively less weight on theoretical expla- 
nations. particularly those that seek precise characterizations of individual cognitive structures and processes. While explanations at this level are valuable. they often fail to capture and incorporate the richness of classrooms and other social contexts of the systems in which people work. In our view, this richness suggests one important reason for the well-recognized failure in the model of research-to-practice dissemination as a linear flow from science to the classroom. Educational practitioners rarely have the causal design understanding to apply the findings from these limited contexts to their situations in larger scale settings. and researchers have not informed their studies by the richness of questions that arise from the dilemmas of situated educational practice. The design perspective thus challenges the traditional basic-applied research distinction, and the presumption that educational settings may improve through the "application" of basic research done outside those settings.

Complexity is thus a second reason for the design focus. Design enterprises by their very nature embrace situational complexity and seek to manage it through to solutions. Recently. Salomon (1991) made this point when he suggested aircraft design as a quintessential activity that must embrace complexity in order to reach solution. Similarly. classroom teaching and learning is such a complex multifaceted enterprise. To improve such an enterprise, the design perspective suggests that one must engineer solutions informed by a deeper understanding of these situations.

A third reason for focus on the design perspective is that design is often what Bruner (1996) calls an "interpretive" activity, rather than one strictly predictive in nature, as many laboratory studies seek to be. Designers most often interpret the results of a design effort strictly bound by the context. Rather than seeking universals, designers seek continually richer characterizations of context or situations in order to understand the practical limits of design solutions. The cases provided by design experiments thus often have their impact primarily by offering inspiration and models for others.

While design experiments offer a new layer of complexity in the analysis of teaching and learning situations, they also have significant limitations. For the most part. they are not implemented in typical classrooms. By virtue of the design experiment orchestration. the classrooms studied are made special. The design experiment transforms the classroom by taking control of as many variables as possible, instead of taking classrooms as they exist and studying the evolution of how innovation becomes integrated in practice. To solve problems of large-scale change will require a smaller exertion of control in the environment, in order to understand where the innovation breaks down. 


\section{Testbeds}

The CoVis project and other testbeds represent an extension of the design experiment concept that better addresses issues related to scale. Testbeds share with design experiments the notion of orchestration. School testbeds are facilities that contain resources for use by the people in schools. One of the key tasks in testbed construction is assembling a community of schools (and/or other organizations) in a way that allows participants to take ownership in and use the testbed resources. In describing the work of educational networking testbeds funded by the National Science Foundation. Hunter cautioned that they cannot be expected to "necessarily succeed in the manner originally envisioned" (Hunter. 1993. p. 97). Because testbed participants are simultaneously engaged in creating and studying classroom reform. it is often difficult to characterize "success" in terms of traditional research measures. Often. characterizations of the creation and maintenance of the testbed itself must be considered as primary results. In these respects. the testbed as a research setting is similar to the design experiment.

Testbeds, however, operate on a significanty larger scale than the design experiment. If design experiments introduce new levels of complexity and variation over laboratory studies, testbeds increase that variation by another order of magnitude by working simultaneously with a broad variety of schools. Testbeds like CoVis strive to test their ideas by implementing them in a range of settings that represent larger scale and greater diversity. The kinds of questions that testbeds are best suited to address deal with the design and appropriation of services by different groups. In this context. "services" are things like opportunities to engage in various forms of curriculum activities, or the chance to use one or another form of technology or other new resources in classrooms. If a design experiment is successful in implementing a new approach to learning in a single or several classrooms. testbeds are only satisfied in finding ways to foster innovation in hundreds of classrooms. The key questions for testbeds are those having to do with understanding the conditions and constraints which encourage and those which discourage the classroom appropriation of a designed resource. At another level. testbeds provide opportunities to investigate how the appropriated resources and services impact on teaching and learning for people in different contexts.

\section{Reform Consortia}

At the high end of situational diversity along the research continuum depicted in Figure 1 are what we will call "reform consortia." Examples include the Co- 
NECT schools (Olds \& Pearlman. 1992) and the Coalition of Essential Schools (Sizer, 1988). Whereas the testbeds conduct their work at the level of many classrooms, reform consortia conduct theirs at the level of many schools. This shift introduces a range of new potential complexities dealing with the interrelationship between various components of whole-school systems. Research conducted in these settings is usually quite far removed from the cognitive processes of the individual learner, although it must benefit from what is learned at all the other levels. This type of research is commonly characterized as closest among our four paradigms to the concerns of educational policy, and often studies the ways in which organizational structures and incentives influence patterns of activity and change.

\section{An Ecology of Paradigms}

In comparing and contrasting these four research paradigms, it is important to remember two things: each has its own forms of complexity. and they are by nature not equivalent. Laboratory research has as many complexities as school reform research. but they are of a different kind. School reformers tend not to worry about controlling instructional variables or the specifics of one student: mental model of electricity after working with a computer simulation. but they may need to worry about school board politics, labor unions, and where mone! flows in school decision-making. Laboratory researchers on science learning need to design sound experiments with well-delineated constructs and may ignore new science education standards, but design experiment researchers must make sure that students in their classroom are receiving an appropriate education.

Finally, it should be clear from the different kinds of questions that each research paradigm invites that these different approaches cannot provide either the research or educational communities with equivalent kinds of answers. For instance, no combination of small design experiments will be likely to yield the same insights into providing new kinds of educational services that a testbed project is liable to yield. Moreover, a testbed, even if it deals with thousands of science classrooms, is not prepared to address design issues in the overall structure and functioning of school systems. Nonetheless, it is important to stress that each level must look to the others in order to ensure that the entire research enterprise does not become irrelevant. Moreover, the largerscale research enterprises can serve as fruitful settings for the conduct of research in each of the smaller-scale paradigms. In this sense, the world of educational research can be seen not as one of competition among paradigms. 
but as maintaining a type of ecological balance among species of inquiry across the diversity of their ecological niches.

\section{CONSTRUCTING THE COVIS TESTBED}

The CoVis project is founded on the premise that classroom science learning should more closely resemble the open-ended, inquiry-based approach of science practice. Our approach to science education was developed as a combination of several current strands of research in the cognitive sciences of learning. Chief among these is the conception that, long before and also outside of formal education, people have learned through participation in communities of practice (e.g., Lave \& Wenger. 1991). The advantage of such communities. in contrast to the regimens of "delivery-oriented" instruction common today, is that learning is situated with respect to community-based goals and activities in which knowledge is developed and used (Brown et al., 1989; Pea, 1992: Songer. 1996). In the classroom. this advantage may take the form of what Collins et al. (1989) called cognitive apprenticeship, with students guided, both by their teachers and by remote mentors, to think about science in many of the fundamental ways that scientists do.

Understanding how people in schools become part of and use distributed resources including human and technical expertise is another key cognitive science issue for the CoVis project (Pea, 1993b: Salomon, 1993). The testbed design goal is to understand how what learners can achieve in inquiry activities in the testbed is developed by means of the tools and people that come together in inquiry tasks there. Put another way, in approaching the design of testbeds as a problem in distributed cognition. we seek to understand how to support learners in "thinking with" a new set of resources when they are readily at hand.

The point of science education. as we construe it, is not to take the "little scientist" that Piaget said was in every child and make them become an actual scientist. In recognition of this separation, our goal was to design settings in which students could become what Lave and Wenger (1991) have called "legitimate peripheral practitioners" in communities of science practice. Furthermore, we used computer and telecommunications tools to facilitate those cognitive apprenticeships (Collins, 1991). CoVis classrooms participate in what we have called "distributed multimedia learning environments" (Pea, 1993a; Pea \& Gomez, 1992). and they enable the activity of "distributed science learning" that we believe will become increasingly 
prevalent in educational settings. The constituents of the CoVis testbed represent our designer's vision of the components needed to bridge a distributed science learning community.

\section{People}

The ket to CoVis functioning as a testbed is the people who comprise it. Students are newcomers to the world of science. The scientists. in CoVis represented by the Department of Atmospheric Sciences at the University of Illinois. Lirbana-Champaign (UIUC). are a group of scientists and graduate students committed to both cutting-edge research in meteorology and educational outreach to students whose future may be either directed towards science or enriched by it.' In the middle ground are teachers, who seek to introduce their students to the world of science as mediators between students and scientists. Researchers (at Northwestern and other sites) serve as facilitators. seeking to understand how this community functions. and both inventing and brokering new opportunities for various members to interact with and learn from one another. A critical part of the CoVis effort involves building productive bridges between these communities. Central to the design effort is reshaping these bridges as we learn through experience with the testbed.

\section{Technolog:}

One set of bridges among these testbed participants is enabled through communication and information technologies. Among the founding premises of our technology design efforts was the importance of circumventing the "trickle down" effect. which results in a nearly decade-long delay between the introduction of technologies in business and research settings and their appearance in K-12 settings (Blaschke et al.. 1987: Roberts, 1988). This delay has the almost inevitable result that students work with out-of-date tools and information (Pea \& Gomez. 1992). a particular problem in science education (National Research Council. 1996).

Our first step towards alleviating this problem was to construct a first-rate communications technology suite for students and teachers. This included high-speed Internet connectivity to the desktop. plus a full suite of standard Internet technologies. including electronic mail. Usenet news. and FTP (later. as they were developed and introduced, CoVis classrooms were among the first

1 The CoVis project grants supported the development of the highly trafficked UILC weather resources of the gopher-based Weather Machine (Ramamurthy \& Kemp. 1993) and. once Web browsers were available. the Daily Planet (Ramamurthy et al.. 1996). The Exploratorium established its tirst "virtual visitor" facilities as a CoVis partner, and through CoVis collaborations first begin to concretely explore using its rich resources to support distributed learning. 
to have access to Gopher and then the World-Wide Web). A unique aspect of the CoVis project was that each individual student received his or her own account and thus a network identity.

Another technology we sought to integrate was desktop videoconferencing -still new in 1992 even in white-collar settings. although the vectors of cost and performance indicated to us that it could become widely accessible in education and consumer markets within a decade.

Yet another communication tool. the Collaboratory Notebook. was developed especially by the CoVis project to scaffold the process of science inquiry in students" project work (Edelson \& O* Veill. 1994: Edelson et al.. 1996:; O'Neill \& Gomez. 1994). We describe experience with its uses in the CoVis testbed later.

Our CoVis Web server (http://www.covis.nwu.edu). planned and launched in early 199+ (Gordin et al.. 1996a: Peal et al.. 1994). provides a common space for all community members. and has evolved in the past two years to serve as a repository and guide to project pedagog!. software. data and curriculum activity resources, as a gateway for teacher communication forums and support. and in the traditional mode as a distriburion medium for dissemination of project publications and news.

Also arailable on the Web is a mentor database. launched in the fall of 1996. to facilitate collaboration between students and outside experts ( $0^{\circ}$ Neill. 1998: $0^{\circ}$ Neill et al.. 1996). The components of this itlecommunications technology suite are in constant flux. being redesigned to meet the evolving demands of the Covis community (Peal et al.. 1997).

\section{Curriculum}

In its very earliest days (starting in 1992). working with two nearby schools. the CoVis project needed to focus primarily on participatory design and testing of soltware and networking technologies. The main forum for participatory design involved coenvisioning. in the context of their practices. possible new technology designs, curriculum activities. and the pedagogical opportunities and challenges of a collaboratory testbed. In this period. curriculum planning was conducted in informal social interactions among teachers and researchers. Common activities between the schools helped to provide context and structure for communication between different communities of practice (McGee. 1996).

As the testbed grew, and as teachers came to a deeper understanding of what they needed in order to make regular. meaningful use of networked resources 
and visualization tools and data sets, we developed larger and more integrated sets of activities. We have come to refer to these larger sets of activities as CoVis Interschool Activities (CIAs). The World-Wide Web was the primary medium through which these activities were shared with teachers. a number of whom were integrally involved in the design and refinement of these activities. both in face-to-face summer workshops. and in the context of their ongoing teaching. In addition to learning about the activities through the Web. teachers engaged in these activities formed communities of interest through listservs. Four different CIAs were developed during the 1995-1996 academic year: one on the topic of land use management. another on global climate change, a third on atmospheric science. and a fourth on soil science.

The CoVis Interschool Activities have been designed to help teachers think about different aspects of project science. educational telecommunications. and collaboration. Each involves opportunities for remote mentoring. and uses of the diverse set of Internet communication tools we have described. Each is also supported with such CoVis Web resources as scientific visualization environments. data sets. collaborative support. and sample assessment rubrics. The key design challenge in creating these activities is to offer enough structure so they can be completed in a classroom context under such constraints as limited time and classroom management concerns. while nonetheless providing enough freedom in the intellectual environment so that learners" questions may be developed as novel project directions.

These activities. provided as a service via the Web. have become a key aspect in the construction of the CoVis testbed. The currency of the classroom is curriculum and activities. The testbed is meant to be a community. Curriculum and activ ities. guided by conceptual foundations. are an important part of the glue that binds the community together and allows the participants to see themselves as a community. with common directions and practices. In addition. they offer a venue where teachers. in the context of listservs. can collaborate with and support one another as they engage in new efforts. seeking to interpret and extend the CoVis vision in new ways. These activities are one of the most important means by which the CoVis community of teachers develops common concepts and practices. It is in the doing of these curricular activities. whether in inter-classroom collaboration or among students within a single class (the common mode). that teichers and researchers have developed common ground about how to do inquiry projects in the classroom and to support them effectively with technology. 
Teacher development

Another critical bridge component in the Covis project is professional development for the teachers who participate. Among the topics that require forums for support and practice are assessment. classroom management. technology and Internet skills, and support for inquiry learning. CoVis has always run summer workshops, giving all members of the community, but especially teachers. the opportunity to briefly come together face-to-face and ask questions. brainstorm. and share their learning and concerns. During the academic year. professional development is supported via electronic mail. using a format similar to that of the Mathematics Learning Forums run by the Center for Children and Technology (Honey at al.. 1994). The on-line forums were to provide a place where teachers could discuss design and implementation of unfolding CIAs.

\section{Schools}

At its start in the 1992-1993 academic sear, the CoVis project worked exclusively with two high-school partners in the north suburbs of Chicago. Six teachers taught twelve sections of earth science. environmental science. and science-technology-society. involving approximately 300 students in total. Later. during the 1995-1996 school vear. we expanded our CoVis testbed to over 40 high schools and middle schools. In this phase of our research. we sought to extend the lessons learned in the tirst phase to achieve these innovations on a larger scale. with greater diversity in the geographical sites and student demographics of participating schools. and to understand how to make these cultural, technological. and curricular innovations sustainable. In this phase. we have been working with over 100 teachers and more than 3.000 students. In the early years of the project. from 1992 to 1994. our six teachers received individual attention from Covis researchers. and each school's technology suite was designed. funded. crafted. and maintained by CoVis staff and partners. In the second phase of work. to create and study the scaled-up CoVis testbed. each school has been responsible for financing and assembling their own technology suite with guidelines and guidance provided by CoVis staff and other community participants). Moreover. on this much broader scale, relatively few classrooms can now be physically visited by CoVis staff because of constraints imposed by distance, time. and budget considerations. 


\section{EXTENDED EXAMPLES OF TESTBED RESEARCH}

In the remainder of this paper, we offer two extended examples as cases of how technologies designed to support learning and teaching in telecommunications-intensive. inquiry-oriented classrooms are appropriated by the user communities participating in the CoVis testbed. We have chosen the cases of desktop videoconferencing. and special groupware we dereloped for the Covis project called the Collaboratory Notebook. for several reasons. The first is that these two communications plattorms were integral to the CoVis guiding framework-we sought. from the earliest instantiation of the project to invent applications of high-performance computing and communication for highly interactive learning environments. We sought to model aspects of our testbed design on the new practices of the scientific community and the business world as it was bringing these powerful resources to bear on erolving its work practices. Our goal was to leverage the "grand challenge" directions of the High Performance Computing and Communications Program of the US Office of Science and Technology policy for the needs of tuture science education. Two of these directions were in tools to support collaboration and scientific risualization. We have focused on scientific visualization in other publications (Fishman $\&$ D’Amico. 1994: Gordin \& Pea. 1995: Gordin et al.. 1994).

In terms of the CoVis hallmark theme of collaborative activities among scientists. Pea and Gomez were inspired by the "collaboratory" concept coined by Bill Wulf (currently President of the National Academy of Engineering) and captured in a 1989 Rockefeller University workshop funded by the XSF (Kouzes et al.. 1996: Lederberg \& Uncapher. 1989). In CoVis. we sought to invent a design and to begin to implement a testbed for the future of science education which shared this image. but recognized the unique needs of educational settings and the constructivist perspective on student learning through project inquiries.

Our second reason for choosing these examples is that they provide us with fascinating examples of what happens when futuristic visions of distributed. "shared media spaces" for science learning and teaching meet the work practices of science education. in today"s classrooms and educational systems. and with today's levels of accessibility of computing and telecommunications by children and teachers. 


\section{Desktop Videoconferencing}

The evolution of desktop videoconferencing technologies within the CoVis testbed provides a salient example of how testbed projects continually refine and redesign services within the context of particular activities. We viewed videoconferencing as a new "class" of technology for classrooms, a new service with new opportunities to offer its users. To help foster its adoption in classrooms. a community of users was constructed to contain students. teachers, and the scientists that we believed important to discourse in CoVis classrooms. CoVis researchers worked together with teachers to orchestrate the use of videoconferencing tools in classrooms. What actually happened with videoconferencing in CoVis classrooms was a surprise to the research team. The story that follows explores design choices made with respest to videoconferencing. and how classroom responses to those choices helped shape a new generation of design decisions.

When the CoVis project started working in classrooms, it was necessary to use a relatively high-end circuit-switched videoconferencing system called Cruiser (Phase I. below). After four years of classroom work and extratordinary technology advances and cost reductions in the networked digital video industry, we now use the freely available (and decidedly low-end) CU-See.Me as our primary videoconterencing application (Phase If. below). The path between the two end points involved the situated learning of testbed participants. including researchers. teachers, kids. and industry partners. about issues of critical mass, software design. and classroum culture.

\section{Phase I: Cruiser}

At the start of the CoVis project. it was clear that videoconferencing had made inroads into education primarily as a technology-mediated version of the traditional lecture. under the label of "distance education" (Peal \& Gomez. 1992). Students typically had little opportunity for interaction with the instructor, and no facility for small group interaction (Pail. 1994). In order to establish the more constructive vision of a distributed multimedia learning environment. the CoVis project sought to build desktop videoconferencing services that emphasized personal interaction between and among learners. and. in particular, support the kinds of knowledge-building acivities that we believe are critical to science learning (Pea \& Gomez, 1992). Working together with the teachers. we envisioned a variety of activities that involved Cruiser. We imagined that Cruiser would be used to put students in touch with mentors, particularly the atmospheric scientists at the University of Illinois. We imagined that students 
would take "virtual field trips" to the Exploratorium museum in San Francisco to see exhibits that explain the phenomena being studied. We imagined that students would contact their project partners in other classrooms to coordinate group work tasks or discuss work-in-progress. And we imagined that students and teachers would engage in collaborative evaluation of shared artifacts together, such as weather maps.

In conjunction with research partners at Bellcore, CoVis planned to introduce the Cruiser desktop videoconferencing system (Fish et al.. 1993) for classroom use. Cruiser was a high-performance communications tool that enabled multiple users to communicate using audio and high-quality full-motion color video. and one of the first available videoconferencing tools built to have computer-based "phone book" capabilities. Like other videoconferencing tools that would become commercially available several years later (e.g.. PictureTel). Cruiser was designed to be used over the public telephone network. which meant that in theory it could be expanded to include nearly any location in the world. During this initial phase of the CoVis project. howerer. Cruiser was available in only six locations: the two high schools. Northwestern. the Department of Atmospheric Sciences at the University of Illinois at UrbanaChampaign. the Exploratorium in Sun Francisco. and Bellicore.

By current standards. Cruiser required a complex arrangement of components in order to operate. In addition to a computer. an external television monitor and microphone were required, and of course a video camera (see Fig. ? for an example of a typical set up). The Cruiser signals were transmitted over a network that was separate from the regular computer data network, but coordinated by signals sent between computers. This meant that use of Cruiser did not impact on use of other computer network applications being used in the school at the same time. Cruiser was a "circuit-switched" system. meaning that, when you placed a call, you were guaranteed a pre-determined amount of bandwidth $(38+\mathrm{Kb} / \mathrm{s})$ exclusively for that purpose. The benefit of reserved bandwidth is quality. In videoconferencing that uses packet-switching (as CLiSeeMe does on the Internet). the available bandwidth is shared so that the quality of video at any moment varies as a function of the volume of traffic on the network. From the perspective of users. circuit-switched videoconferences have consistent high quality. while packet-switched conferences can be extremely variable. Our initial goal was to offer schools the best quality video practically possible, particularly since they would be doing "virtual travel" to the Exploratorium Science Museum in San Francisco. and good video resolution would be a key requirement for users to perceive the dynamic qualities of 


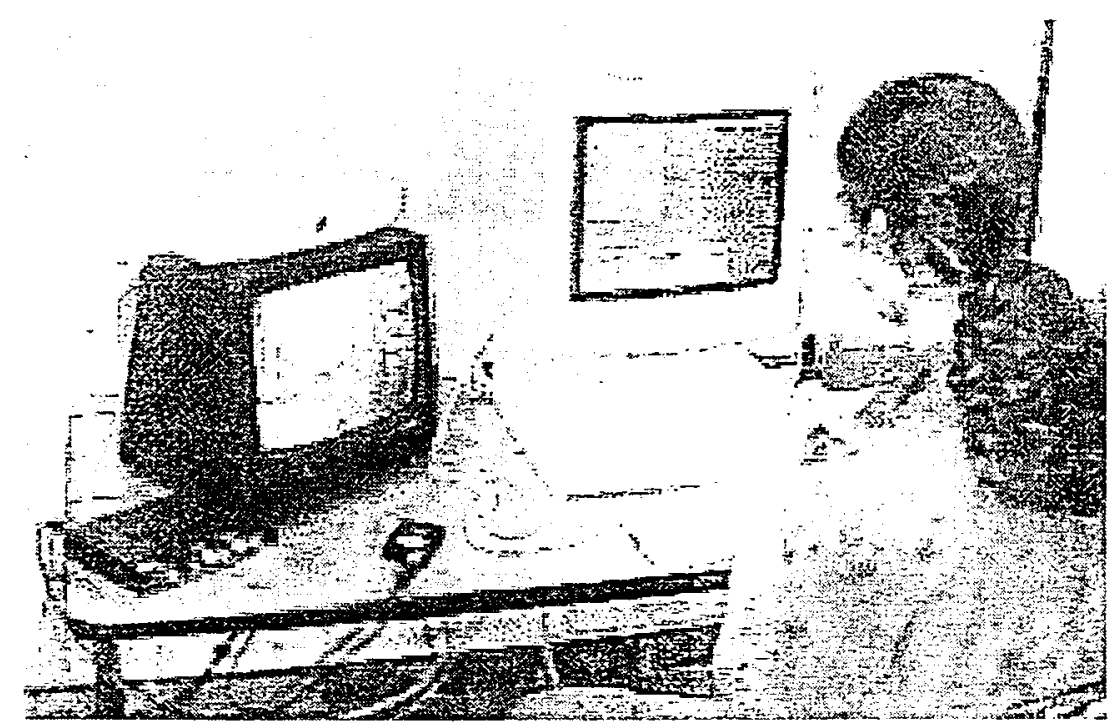

Fig. 2. Ty pical Cruiser contiguration in a Coli. s...s.rom.

its exhibits. To facilitate the sharing of distal artifacts. such as weather maps. we used the screen-sharing software from Falisllon called Timbuktu. This software allows two computers to act as if the: halve only one shared monitor between them. even at a distance over the Intemes. The result is that people having a conversation over Cruiser can use the molise to point at objects on the screen. and that pointing for virtually any other activity on the computer screen) is seen by the person on the other end.

In our initial discussions with teachers. Croiser was viewed with great interest. This was understandable. as videoconterencing clearly offered the most immediately comprehensible and dramatic of all the new technologies being introduced to their classrooms. Scientific visualization. the Internet. and collaborative groupware took longer to comprehend.

Together with the teachers. we envisioned a variety of scenarios for using desktop videoconferencing in students collaborarive project inquiries. These included distributed viewing of a common video or joint participation in a virtual field trip to spur topical discussions and questions in the project development phase. video visits with staff of the science laboratories or the Exploratorium for advice during projects. "shared media spaces" across schools between members of student project teams. and distributed presentations of CoVis projects by students over the . Net, so thit commentaries and 
assessments of projects could emerge from the learning community across the schools and scientific groups involved.

As researchers, we were also very interested in the success of Cruiser because it offered a real-time bridge between the communities of schools and scientists. Furthermore. Cruiser also required a sizable investment of funds to become operational. including hardware for video compression and decompression ("codecs"). cameras. monitors, and personnel to help set it up. debug it. and keep it running. In the category of "high-risk, high reward" research. Cruiser was certainly a top contender.

Yet. even with the extra emphasis placed on it in the overall design of CoVis classrooms. Cruiser was hardly ever used in daily classroom life. Tracking of the use of all computer-mediated computer tools during the $199+1995$ academic year showed that while students sent over 10.000 e-mail messages. posted over 1. $\$ 00$ Usenet news articles. and created over 1.100 pages in the Collaboratory Notebook. there were only 32 Cruiser calls placed across all 13 CoVis classrooms (Fishman. 1996). How can the extremely low use of Cruiser be explained?

A key explanation for this low use of Cruiser is a mismatch between classroom culture and the affordances of videoconferencing. Although teachers readily accepted the challenges of creating highly collaborative and interactive classroom environments supported by asynchronous tools (e.g.. e-mail. Usenet news. CoVis Collaboratory Notebook, within their classrooms. they were more reluctant to include synchronous communication tools in these environments. Reasons for this that emerged over time included issues of coordination with distant partners. and problems with the presumed ease of translating the "office drop-in" model of use for Cruiser videoconferencing in a corporate work environment to classrooms in schools. In the white-collar workplace. Cruiser was used to create extended workspaces. helping to foster the kind of informal interaction that people have while "cruising" the hallways of their office space (Fish et al.. 1993). Teachers did not like the thought that somebody could interrupt their classroom activity without warning. So Cruiser stations in classrooms were as a matter of practice not left running. which is the videoconferencing equivalent of taking your phone off the hook-nobody can call you. Other problems had to do with the tight windows of available time that any single classroom could be on-line. Whereas in the white-collar environment one might reasonably expect to find someone at their desk at any time during the day, in the classroom environment particular students are only typically present for 40 minutes at a time. While it may be possible for a scientist mentor to adjust her 
schedule to be available during a particular class period. the problem becomes much worse when two teachers or students at different schools wish to communicate. Since school time is rigidly structured. special arrangements must be made to facilitate interaction between two parties who do not happen to have cliss during the same hour. The classroom environment is significantly different from white-collar settings, and we found that it does not readily support the adoption of synchronous tools (Fishman. 1996).

Other cultural concerns were expressed. Teachers noted their worries that students would mainly use the videoconierencing for social purposes. and "getting dates." In addition, the belief we had that teachers might share in the assessment task for collaborative student projects across their classrooms and schools was problematic in several respects. First. it presupposed that interclassroom project teams would be commonplace. Secondly. it assumed that teachers would negotiate a common ground around assessment rubrics for their students' project work. Both assumptions we:e violated. Neither had a footing of existing cultural practices to stand on. Giten the newness of extensive project-oriented work within the classroom. and its novel assessment challenges, teachers generally preferred to keep their projects to groups within the classroom. While there were exceptions. they did not tend to call upon Cruiser as a new media vehicle to support collaborative learning in the CoVis testbed.

Finally. Cruiser did not support communication between CoVis students and relevant outside populations. While there were some scientists that students could communicate with (at the Exploratorium and UIUC). the vast majority of students established connections to outside mentors and others using electronic mail. which was more widely arailable and allowed for students and outsiders to communicate on their own. non-synchronized schedules. Thus. Cruiser was also prevented from flourishing due to the lack of what media theorists have called "critical mass" (Narkus. 1987).

\section{Phase II: CL-SeeMe}

The low use that Cruiser received was worrying to Covis designers as the project began to grow from the initial two schools in $190+$ to the current testbed of over 40 schools. Budget restrictions would require limiting the installation of Cruiser to only six schools in the new testbed. Our original plan was that there would be a "community within the community" of high-bandwidth ,chools equipped with Cruiser. and a broader community that would rely prinarily upon e-mail and other lower-bandwidth forms of communication. Our lew understanding of Cruiser's low use in terms of critical mass suggested that 
in a scaled-up CoVis project, if we took this approach, we would be condemning videoconferencing to permanent marginality. Rather than invest in a communications tool that only a few could use. we instead began to look for viable alternatives that would enable the entire community to participate in videoconferencing.

During the time that CoVis was experimenting with Cruiser. a new form of videoconferencing tool was starting to emerge that used TCP/IP. or Internet protocols. as its transport mechanism. The premier example of this type of tool was CU-SeeMe, from Cornell University.- The primary technical advantage of this software was that it enabled extremely low-cost videoconferencing--a school's investment in Internet connectivity also provided a video network. The primary technical limitations for this software in its early stages was the lack of integrated video and audio. and the sometimes complicated process of introducing video into one's computer system. In addition. because of the variable bandwidth limitations of the Internet. video quality could be quite low. These tools are "packet-switched" (as opposed to "circuitswitched"), which means that they must share bandwidth with all the other services in use on the network. Average frame rates for $\mathrm{CL}^{\prime}$-See.Me were between five and eight frames per second of black-and-white video. compared to Cruiser's 25-30 frames per second of color video. And. at least initially, you needed to use a telephone to provide audio (and telephones are often even rarer in classrooms than Internet connections). Even with these limitations. some educational projects had started to experiment with CU-SeeMe as a way to provide a virtual presence between classrooms, primarily the Global Schoolhouse Project.

In early 1994, two technological developments made it possible for the CoVis project to consider CU-SeeMe as a replacement for Cruiser. The first of these was the introduction of synchronized audio in the CL-SeeMe software. using the computer's built-in microphone as the source. The second was the introduction of the Connectix QuickCam. a low-cost digital camera (widely known as the "eyeball" camera for its shape) that required no additional hardware to get video into the computer. These new developments meant that most CoVis schools could now afford to participate in videoconferencing activities.

During the 1995-1996 academic year, videoconferencing using CU-SeeMe began to take root as part of regular CoVis activities. While the cultural issues

2 CU-SeeMe is available for free from http://cu-seeme.cornell.edu/ 
of synchronous tools are still present, the difticulties associated with complex hardware and software have been greatly reduced. and the critical mass problems have been minimized. We worked to ameliorate the cultural problems caused by synchronous communication through scaffolding and structuring its use in interschool curricular activities.

One example of videoconferencing activity embedded within a larger curricular context was a model summit on global climate change, held as a culminating activity for a month-long set of activities on climate change (Gordin et al., 1996b). While not all schools chose to participate in the video conference-based summit, it is noteworthy that the schools taking a leadership role in this activity were both middle schools. Teachers and students in these two middle schools had flexible schedules. and met for extended periods on most class days, thus facilitating the synchronous interaction. Another desktop videoconferencing activity was a regular "interactive weather briefing" between an atmospheric scientist and groups of students seeking to interpret current weather maps. A third type of activity was the "virtual field trip" between various schools and the Exploratorium Science Museum. Using a backpack equipped with a video camera and a remote link to the Internet, museum staff in San Francisco were able to lead short tours of various exhibits at the museum. directed by students using $C L^{\prime}$-See.le. A fourth type of use. unanticipated by the designers at the start of the sichool year. was the use of Cli-SeeMe to supplement parent-teacher meetings and informational sessions. This allowed staff at Northwestern to be invited "into" classrooms in order to answer questions about the various acrivities students were engaged in as part of CoVis. This combination of ways that CU-SeeMe based videoconferencing has been employed by CoVis teachers and students is an important indicator of its successfully taking root in classroom culture. especially when compared with Cruiser.

A weakness of Internet-based videoconferencing systems is that they take up so much bandwidth that it is not possible to simultaneously use screen-sharing software such as Timbuktu. Yet this goal of shared media spaces was integral to the CoVis project vision (e.g.. Pea, 1993a. 1994). What we sought in the 1992 grant was to: "extend collaborative media beyond asynchronous text-only e-mail to shared workspaces and two-way audio/video connections that allow for collaborative visualization of science phenomena. data. models-What You See Is What I See (WYSIWIS). Tools for local- and wide-area networked leaming environments will enable highly interactive. media-rich communications among learning partners." 
One possible solution to this problem may lie in the construction of websites where meeting participants can store the work to be discussed in advance. Another solution is to introduce a shared whiteboard facility that can be used to exchinge screenshots. The notion of shared whiteboards is not new (e.g.. Tang \& Minneman. 1991). but full integration with videoconterencing tools is a useful addition. especially in classroom settings where simplification of software is highly valued.

Videoconferencing tools and services. as an example of technology adoption within a testbed setting. provide a compelling lens through which to view the distinction between intentions (design) and enactment (real use by teachers and students). In CoVis. design decisions about videoconferencing were made first from the basis of what we wanted CoVis classrooms to look and be like. and then revisions had to be made based upon what they actually were like. The tested made it verv clear to CoVis researchers that classrooms are very different settings for the use of videoconferencing tools than the whitecollar or research environments where they are designed. Emerging technologies. like CL-See.Me. made it possible for CoVis to find a design response to that challenge. and leave us optimistic about the potential for Internet-based videoconferencing as a regular feature of science education in the future. The next section. about the design and classroom use of the Collaboratory Notebook. is about a different kind of testbed research and design opportunity: a tool and service designed in response to the emergent needs of the classroom environment.

\section{The Collaboratory Notebook}

As the CoVis project evolved. a need developed for a special purpose telecommunications tool to support student inquiry and project-enhanced science work in classrooms. This tool became the Collaboratory Notebook (CNB). which is intended to be a cross between a scientist s laboratory notebook and a networked hypermedia database. The development of the CNB provides insight into how specific telecommunications needs arise in a testbed environment. and the subtle interplay existing between designers and participants that affects how such tools are both adopted and adapted in a cycle of "appropriation" (Pea. 1992: Polman \& Peil. in press). This extended example hils three parts: first, the design and initial deplovment of the $\mathrm{CNB}$, with reflections on its initial classroom uses: second. student-level research conducted as the tool "matured" in CoVis classrooms. yielding insight into why some students use CMC tools like the CNB more than other students: and finally, a discus- 
sion of CNB design issues that became apparent only in the scaled-up testbed, leading to an extensive re-implementation of the CNB. ${ }^{3}$

Because of the complexity of testbed development environments, the CoVis team sought to use existing technology wherever possible. Examples include Cruiser videoconferencing (discussed above) and electronic mail, both of which were brought into the CoVis environment with few changes from the way they have been used in other environments (i.e.. white collar research settings). In contrast, the Collaboratory Notebook was conceived of as a tool that would support three of the key themes of the CoVis project: project-enhanced science learning. visualization, and collaboration. Specifically, a tool was required that would support students and teachers in the unfamiliar task of performing prolonged inquiry. provide a means of integrating visualization artifacts with other classroom work (computational and non-computational), and it needed to support collaborative work. especially among partners that might not be colocated (Edelson \& $\mathrm{O}^{\circ}$ Neill. 199-). Before starting work on a new tool. we carefully considered existing tools that might have served our needs. These included commercial products. such as Lotus Notes. and research products. such as INQUIRE (Hawkins \& Pea. 198\%), and CSILE (Scardamalia et al.. 1989), which was a local-area networking "knowledge building" environment for a single class at a time.

Although many of the features of those arlier collaborative tools provided design inspiration for the software that eventually became the CNB, none of them provided the functionality that we believed necessary for supporting the complex web of goals in the CoVis project. In particular. CoVis required the combination of wide-area network connectivity and structured support for project-based inquiry. As an asynchronous communication tool, the CNB was designed to facilitate work between partners who are in different locations and unable to work at the same time. We considered this essential for students working in different classrooms. or for scientists collaborating with students or commenting on their work. Furthermore. the CNB has a TCP/IP clientserver architecture. allowing users access to a common database of notebooks

3 The design of the Collaboratory Notebook has been described in other forums and will not be repeated here. For more information and interfice sureenshots. refer to Edelson and O'Neill (1994), O'Neill and Gomez (1994). or Edelson. Peal and Gomez (1996b). The needs identified in the Collaboratory Notebook were important in shaping the current work on the Progress Portfolio in the SIBLE project. enabling reachers and curriculum designers to structure student work by prompting them to reflect on specitic alspects of their progress (Loh et al.. 1998). In constructing the Collaboratory Notebook, the authors would like to specially acknowledge the design and programming work of D. Kerin O'Neill. Myrland J. Gray. and Daniel Edelson. 
wherever there is an Internet connection. Initially, the Fall 1993 CNB prototype was developed only for Apple Macintosh computer systems, and required at least $16 \mathrm{mb}$ of memory in order to operate.

Design assumptions of the $C N B$

In writing about some fundamental design assumptions of the Collaboratory Notebook, O'Neill and Gomez (1994) emphasized the CoVis perspective that learning about science needs to include the social dimensions of science practice, and also that student appropriation of the speech genres of the scientific community are an important part of the enculturation of students into science. The CNB embodies the genres of scientific speech through specific labels for pages and a strict link structure to scaffold student inquiry. For instance. students are encouraged to create "question" pages and then to pose follow-up "conjectures." in response to which they might present "evidence for" or "evidence against" the conjecture. Another important design feature was a table of contents that provides teachers (and. presumably. mentors) with an overview of each student project. The table of contents allows the user to see. at a glance. the progress of the inquiry. including the kinds of pages employed by students. which also has advantages for the assessment of project work-in-progress (O`Neill \& Gomez. 1994).

First year of ciassroom use: Developing and understanding practice

The Collaboratory Notebook was used by 118 students during the first threequarters of the 1993-199+ academic year. in six classes taught by four CoVis teachers (this was during the smaller, two-school phase of the CoVis testbed). During this time period. 59 separate notebooks were created. containing a total of 352 pages. This period of CNB use served as the basis for preliminary research on tool adoption by students and teachers. including an examination of the appropriateness of the design assumptions described above $\left(\mathrm{O}^{\circ} \mathrm{Ne}\right.$ ill \& Gomez. 1994). The methods used by the researchers at this time included close work between researchers and teachers in the style of Hunt and Minstrell (1994). to develop activity frameworks in which use of the CNB was sensible. Data on page creation and other aspects of CNB use were generated automatically by the software. and a combination of observations and interviews with both teachers and students were used in order to form an understanding of the nature of student work in the CNB.

In surveving student use of the $\mathrm{CNB}$ during this period. $\mathrm{O}^{\circ} \mathrm{Neill}$ and Gomez concluded that the design of page labels and tables of contents had found 
"mixed success" in the classroom. In two separate projects, teachers created sample notebooks to serve as models for their students, indicating the types of page hierarchies that they believed to represent well-formed inquiry within the CNB. In terms of use of various page labels by students, there were instances of specific combinations of pages being used to connote particular kinds of interaction. One example is the invention of forms to support revision of project proposals. However, students did not make use of a broad range of page labels. While there were many question, commentary, information, and plan pages, there were relatively few examples of students using the conjecture and evidence pages. In the case of tables of contents. teachers considered them to be a good start for monitoring the progress of projects, but using them was too time-intensive to be viable (O'Neill \& Gomez. 1994).

Second year of classroom use: Student appropriation studies

In the 1994-1995 academic year. the second vear that the Collaboratory Notebook was used in CoVis classrooms. a different kind of research was conducted on student appropriation of this communication tool. This research was primarily quantitative, using surveys of student demographics. beliefs, and attitudes as independent variables in order to form an understanding of factors related to differential use of the CNB among students in CoVis classrooms. In addition. classroom observations. teacher interviews, and student focus groups were conducted to gain an understanding of the nature of student work in the CNB (Fishman. 1996; Polman \& Fishman. 1995). The factors considered in this research included gender, parental education. academic self-concept, computer skill and experience. skill with the C.YB. typing ability, and communication apprehension. Communication apprehension is a measure of reticence to communicate using written media (Daly \& Miller. 1975). Data on these factors were all student self-report (except gender).

We looked at these factors in an effor to understand how broad-based demographic aspects of classrooms might have an impact on the utility of a technology like the Collaboratory Notebook. The subjects for this research were students in three teachers' classrooms of the six teachers participating in CoVis at the time. or seven out of a total of twelve sections of students. Students created a total of 1.114 pages in 270 different notebooks in the CNB during this academic year. ${ }^{-}$

The following factors were found to be positively related to student use of the Collaboratory Notebook: academic self-concept $(r=.319, p<.01, n=$ 139). overall skill with computers $(r=.288 . p<.01, n=101)$, typing

+ For purposes of comparison. students sent 10.450 e-mail messages and posted 1.417 Usenet news articles during the same academic year. 
Table 1. Multiple Regression Model Where $R^{2}=22.4 \%$.

\begin{tabular}{lllll}
\hline Factor & $B$ & $S E B$ & $B$ & $p$ \\
\hline Parents" education & 1.133 & 0.3434 & 3.30 & $<0.01$ \\
Skill with CNB & 1.62 & 0.65 & 2.51 & $<0.02$ \\
Overall computer skill & 0.23 & 0.12 & 1.90 & $<0.06$ \\
\hline
\end{tabular}

ability $(r=.275 . p<.01, n=108)$, skill with the $\mathrm{CNB}(r=.346, p<.01 . n$ $=115)$. and parental education $(r=.291 . p<.01 . n=128)$. Neither gender nor communication apprehension was found to be related to student use of the $\mathrm{CNB}$. Students who had computers at home did create more notebook pages $(M=8.79 . S D=8.31, n=103)$ than those who did not have home computers $(M=4.58 . S D=4.42 . n=36)$. These means were significantly different $(t(137)=2.89, p<.005$, two-tailed). This difference is not attributable to haling increased access to the software, since students were not able to use the Collaboratory Notebook on any computers outside of their classroom. Having a computer at home is more likely to be related to a student's overall experience with computers.

Using regression analysis. we can determine how much variation in C.NB use can be attributed to the significant factors listed above. Factors in the final model were parental education. skill with the CNB. and overall computer skill (academic self-concept and typing ability were not significant in the overall model), and the multiple $R$ : accounted for $22.4 \%$ of the variance (see Table 1 ).

What might account for the roughly three-quarters of variance in CNB use not accounted for in the model in Table 1? The most probable candidate is the influence of individual teachers over how and when various telecommunications tools are used in CoVis classrooms (Fishman. 1996). The general flow and direction of activity, even in a project-enhanced classroom, is under the control of the teacher. How students are assessed for using various tools, and the weight given to different aspects of their work. is likely to be an important part of that equation as well ( $D^{\prime}$ Amico. in preparation).

In terms of students typing ability, it is interesting to note that there was a "threshold effect" in terms of predicting the volume of CNB pages created (Polman \& Fishman, 1995). Students who rated themselves as average or above average typists created more pages $(M=9.26 . S E=.87 . S D=8.39 . n$ $=93$ ) than students who rated themselves as below average or poor typists $(. \mathrm{K}$ 
$=4.29 . S E=.68, S D=4.53, n=45$ ). The difference between these means is significant $(t(134)=4.512, p \leqslant 0.0001$, two-tailed). We unfortunately do not know what typing speed in words per minute students considered "average."

As in the research conducted during the 1993-1994 school year, this more focused research on student adoption of the Collaboratory Notebook helped inform the overall design and implementation process. By generating more refined understandings of how and when students take advantage of communications tools. we gain a better perspective on how to design classroom activity (together with teachers) to leverage their presence.

Year three and bevond: Scaling up

As the CoVis project prepared for its second phase. several recruitment meetings were held to discuss with new teachers various aspects of the project. The Collaboratory Notebook was aiways greeted enthusiastically at these meetings. During the CoVis summer development workshop held prior to the start of activities in these new schools, teachers were surveyed to learn what parts of the project they were most enthusiastic about. In these surveys. CoVis teachers indicated that they were interested in using the CNB. The reasons for their interest teachers gave in conversations with CoVis researchers were very much aligned with the original design assumptions as stated by $\mathrm{O}^{\circ} \mathrm{Neill}$ and Gomez (1994). However, even with this initial enthusiasm. there was far lower use of the CNB in the 1995-1996 academic year than in either of the preceding years. even given the much larger potencial audience of users.

Before discussing some of the reasons we believe that CNB was not used by $\mathrm{CoVis}$ teachers, it is worth mentioning that it was used by a range of people and organizations beyond the boundaries of the CoVis community. These included an educational outreach project at Biosphere 2 in Arizona. and a problem-based learning course at Northwestern University's School of Medicine. In addition, requests were made by organizations interested in adapting the $\mathrm{CNB}$ for their own projects. including a museum in Germany, researchers in Italy, the Adler Planetarium in Chicago, the Block Gallery of Art at Northwestern, a quality assurance project at the Illinois State Board of Education, and an NSF planning grant project on mentoring in California. Furthermore. in interview-based research that is underway as of the writing of this paper, CoVis teachers in schools where the Collaboratory Notebook was not used continue to voice enthusiasm for the software, speak of it as a very important component of the CoVis project. and report that they still want to use it in their classrooms (Shrader et al., 1997). 
Why did the $\mathrm{CNB}$ receive little use from CoVis students and teachers in the 1995-1996 school year? One possible reason is that CoVis researchers were not directly involved in the support of CNB use in classrooms, as we had been during the previous two years. As a testbed grows in size, it becomes increasingly difficult to maintain a physical presence in any particular classrooms. including the classrooms of the six teachers who received so much direct attention during the first two years when the testbed was small. Given the range of resources and telecommunications tools available for use as part of the CoVis project, it is conceivable that teachers opted for less complicated tools. even if this choice meant trading away some of the benefits of the Collaborator! Notebook.

In its original form. the Collaboratory Notebook was sufficiently complicated to install and configure that most teachers required extra help from school support staff, which was difficult to obtain. In fact. the CNB installation was so complicated that it was not included as part of the teacher curriculum at summer development workshops, due to time constraints. Instead. technolog! coordinators were taught how to install the software in separate sessions. Thi: might well have been the CNB's downfall. Another potential explanation is the lack of pre-packaged curricular activities that integrate the CNB. In previou: years, these activities were not developed because researchers could work directly with teachers to develop personalized activities.

To remedy these two problems, we have re-implemented the Collaborators Notebook as well as embarking on the design of activities that provide greate: structure for the use of the CNB. The software has been rewritten from the ground up in $\mathrm{C} \div+$. so that it not only runs faster but takes up much less memory. allowing it to be run on the broader variety of computers that are found in: classrooms. Furthermore. an IBM-compatible version of the CNB has beer: developed. allowing access to more schools and mentors in sites that do not have Internet-connected Macintoshes. In addition. an easy-to-use installation program was created. so that teachers would be able to install the softwarc without outside help. During the 1996 summer professional development workshop. all teachers were given practice in downloading and installing the new version of the CNB. As a part of that training workshop. volunteers were recruited from among the teachers to participate in the development of activities that integrally use the Collaboratory Notebook.

A final issue of concern is whether. given the state of computing an: telecommunications in the learning environments of the CoVis testbed, the CNB itself is below an "access threshold" for utility. Perhaps without regular 
use by every learner as an "information appliance" for their project inquiry work. it is not perceived to be a good fit as an information environment for the $\mathrm{CoV}$ is activities. This problem must await for its solution the arrival of inexpensive, Internetworked, highly portable. personal computing devices. Until that time, we are continuing to work on iteratively improving the fit between the CNB and its classroom appropriation by students and teachers to advance science learning through project inquiry.

\section{CONCLLSIONS}

This paper has described a new and growing environment for conducting educational research: the testbed. Testbeds share many of the features of design experiments, but at a scale that fundamentally changes the nature of the relationship between researchers and subjects. The size of testbeds is simultaneously an advantage. because of both the broad variety of research opportunities that are made available in rich and direrse contexts and closer fit between the needs of practice and research. and a liability. because of limitations placed on direct contact between participants and researchers. Research in testbeds is driven by the in situ needs of school communities.

We have presented the CoVis project as an example of a testbed whose research is geared towards designing. developing, and deploying new educational telecommunications resources and services for the classroom. When we offer new services and technologies to schools. these innovations are confronted by the realities of schools as we find them. Unlike design experiments. testbeds have to prepare for and respond to the needs of schools and classrooms in the diversity of forms in which they naturally exist.

In a design experiment, the researcher can reshape the classroom to fit the needs of a curriculum or a technology. Indeed. we were partially successful in shaping use of various CoVis technologies on a small scale, as in the case of Collaboratory Notebook use. However. in the broader context of the testbed. we can see and understand the characteristics of these technologies that allow them to be either appropriated by teachers or fail to take hold in classrooms. Testbeds often allow only incremental reshaping of classroom activity, and the only form of orchestration typically found in the testbed is the willingness of participants to engage in a particular form of pedagogy. The most important ground rule for a testbed is common pedagogical vision on the part of its participants. We hope, therefore. that testbeds will allow us to judge the suitabil- 
ity of an innovation to a variety of classroom contexts. In the case of CoVis. the minimal agreement arrived at between schools and researchers was to work within the context of project-based science and inquiry. As we noted in our examples above. that agreement was not sufficient to surmount the difticulties encountered in our early trials of videoconferencing. This freed us to observe behavior that might not be visible in the more constrained context of a design experiment or laboratory study. The testbed also frees us to continue to refine the roles for researchers and other facilitators in the support of technology in the context of a common pedagogical vision. As we made CoVis services more widely available, it became clear that we had an important mediating role on an ongoing basis as facilitators. That role could not be played by being physically present in all classrooms, and instead became embedded in our curricular efforts through the design of CoVis Interschool Activities. This form of contact. including suggested classroom activities and on-line teacher-to-teacher asynchronous conversation. was sufficient to sustain the use of some technologies like e-mail and scientific visualization but could not broadly sustain a technology like the Collaboratory Notebook. at least in its early form. The testbed provides a venue where we can gain partial purchase on the likely constellation of factors (both human and technological) needed to support new. technologies and pedagogy in a diverse context.

In early 1992. the CoVis project anticipated that collaborative inquiry groupware for students. desktop videoconferencing. and scientific visualization tools and data would become accessible to many schools within a 5-10 year period. These predictions are largely holding true. The scientitic visualization suite. the Collaboratory Notebook. and desktop videoconferencing all now run on Internetworked computers that cost as little as $\$ 1.500$ each. While not all schools have the robust $\mathrm{T} 1$ Internet connectivity that we believe to be necessary. recent government initiatives (including a two billion dollar technology initiative from the President and the nationwide organization of "Net Days" for wiring schools) are opening up opportunities for such connectivity. As a result. the number of classrooms where CoVis-like environments are possible is increasing daily. We believe that creating a testbed centered on the value of these technologies in the support of teaching and learning provides valuable first-order information about the likely adaptability of these technologies to the real diversity of classrooms. Our hope is that other education research testbeds. inspired by these developments, will explore similar new advances of high performance computing and communications in parallel with advances in conceptions of effective learning and teaching in ways the CoVis project has exemplified. 


\section{REFERENCES}

Anderson. J.R.. Corbett, A.T. Koedinger. K.. \& Pelletier. R. (1995). Cognitive tutors: Lessons learned. Joumal of the Leaming Sciences, +. 167-207.

Blaschke. C.. Hunter. B.. \& Zucker. A. (1987). The histon of federal finding for research and development in educational rechnolog!: 1950-1987 (NTIS PB 88-194 626/AS). Washington. DC: Ortice of Technology Assessment. L.S. Congress.

Brown. A.L. (1992). Design experiments: Theoretical and methodological challenges in creating complex interventions in classroom settings. The Joumal of the Learning Sciences, 2. $1+1-178$.

Brown. A.L.. \& Campione. J.C. (1990). Ineractive learning environments and the teaching of science and mathematics. In M. Gardner. J.G. Greeno. R. Reif, A.H. Schoenfeld, A. diSessal. \& E. Stage (Eds.). Tonard a scientific practice of science edacation (pp. II $1-139$ ). Hillsdale. NJ: Lawrence Erlbaum Associates.

Brown. J.S.. Collins. A.. \& Duguid. P. (1989). Situated cognition and the culture of learning. Eclucational Researcher: 18, 32-42.

Bruner. J. (1996). The culture of education. Cambridge. .HA: Harvard University Press.

Collins, A. (1991). Cognitive apprenticeship and instructional technology. In L. Idol. \& B.F. Jones (Eds.). Educational ialues and cognitive instruction: Implications for reform (pp. 121-138). Hillsdale. NJ: Lawrence Ertbium Associates.

Collins. A. 1996). Design issues for leaming emvironments. In S. Vosniadou. E.D. Corte. R. Glaser. \& H. Mandl (Eds.). Intemational perspectives on the psychological foundations of technolon-bused learning envirnments ipp. 3+7-361). New York: Springer-Verlag.

Collins. A.. Brown. J.S.. \& Newman. S.E. 1989). Cognitive apprenticeship: Teaching the crafts of reading. writing. and mathemarics. In L.B. Resnick (Ed.). Knowing, learning, and instruction: Essays in honor of Robert Giciser ipp. $+53-494$ ). Hillsdale. NJ: Lawrence Eribaum Associates.

Corbett. A.T. Anderson. J.R. \& Patterson. E.G. 119901. Sudent modeling and tutoring flexibility in the Lisp Intelligent Tutoring System. In C. Frasson. \& G. Giuthier (Eds.), Intelligent tutoring systems: to the crossiods of arrifial intelligence and education ipp. 83-1061. Norwood. NJ: Ablex.

Daly. J.A.. \& Miller. M.D. (1975). The empirical deveiopment of an instrument to measure writing apprehension. Research in the Teaching or English 9, 242-249.

D Amico. L. (in preparation). The role of assessment infrastructures in crafting project-based science classooms. Lnpublished doctoral dissertation. Northwestern University, Evanston. IL.

Edelson. D.. \& ONNeill. D.K. (1994). The CoVis Collaboratory Notebook: Supporting collaborative scientific inquiry. In A. Best (Ed.). Proceedings of the 1994 National Educational Computing Conference (pp. ! +6-152). Eusene. OR: International Society for Technology in Education in cooperation with the Sational Education Computing Association.

Edelson, D.C., Pea. R.D.. \& Gomez. L. (1996a). Constructivism in the collaboratory. In B.G. Wilson (Ed.). Consmacaitist leaming emiromments: Case studies in instructional design (pp. 151-164). Englewood Cliffs. NJ: Educarional Technology Publications.

Edelson. D.C.. Peil. R.D., \& Gomez. L.M. 11996b). The Collaboratory Notebook. Communications of the + CM, 39, 32-33.

Finholt. T.. \& Olson. G.M. (1997). From libraries to collaboratories: A new organizational form for scientific collaboration. Psycholosical Science, 8, 28-36. 
Fish, R.S., Kraut, R.E., Root. R.W.. \& Rice, R.E. (1993). Video as a technology for informal communication. Communications of the ACM, 36, 48-61.

Fishman. B.J. (1996). High-end high school communication: Tool use practices of students in a nenorked enironment. Unpublished doctoral dissertation, Northwestern University. Evanston. IL.

Fishman. B.. \& D'Amico. L. (1994). Which way will the wind blow? Networked tools tor studying the weather. In T. Ottmann. \& I. Tonek (Eds.), Edacational multimedia and hypermediut (pp. 209-216). Vancouver. BC: Association for the Advancement of Computing in Educition.

Gordin. D.. Gomez. L.. Pea. R.. \& Fishman. B. (1996a). Using the World Wide Web to buili leaming communities in $\mathrm{K}-12$. The Joumal of Computer-Mediated Communication 2 (3). Available: http:/www.usc.edu/depuannenberg/vol2/issue3/gordin.html [Electronic Joumal].

Gordin. D.. \& Pea. R.D. (1995). Prospects for scientific visualization as an educational technology. The Jounal of the Leaming Sciences, 4. 249-279.

Gordin. D.N.. Edelson. D.C.. Gomez. L..M., Lento, E.M.. \& Pea. R.D. (1996b). Sudent conference on global warming: A collaborative network-supported ecologically hierarchic geosciences curriculum. American Meteorological Socien: Fifth Stmposium on Educution (pp. 122-127). Atlanta. GA: A.MS.

Gordin. D.N.. Polman. J.L., \& Pea. R.D. (1994). The Climate Visualizer: Sense-making through scientitic visualization. Joumal of Science Education and Technology, 3. 203-225.

Hawkins, J. \& Pea. R.D. (1987). Tools for bridging the cultures of every day and scientific thinking. Joumal of Research in Science Teaching, 24, 291-307.

Honey. .I. Bennetr. D.. Hupert. N.. Kanze. B., Meade. T.. Panush. E.ML.. Powell, K.. Spielvogel. R.. Dubitsky. B.. Cohen. M.. Melnick. H., \& Peterson. L. (1094). The Mathematics Learning Forums on-line: Lising telecommunications as a tool for reflective practice. Machine-Mediated Leaming, t. 163-176.

Hunt. E.. \& Minstrell, J. (1994). A connitive approach to the teaching of physics. In K. McGilly (Ed.). Classroom lessons: Integraning cognitive theory and classroom practice (pp. $51-7+1$. Cambridge. MA: MIT Press.

Hunter, B. (1993). NSF's networked testbeds inform innovation in science education. T.H.E. Joumal. 2I, 96-99.

Koedinger. K.R.. Anderson. J.R.. Hadley. W.H.. \& Mark. M.A. 199 ミ1. Intelligent tutoring goes to school in the big ciry. Paper presented at the meting of the 7 th World Conference on Artificial Intelligence in Ejucation. Washington. DC.

Kouzes. R.T., Myers, J.D. \& Wulf. W.A. (1996). Collaboratories: Doing science on the Internet. IEEE Computer, $40-+6$.

Kulik. J.A.. \& Kulik. C.C. (1989). Meta-analysis in education. International Journal of Edtucational Research 13(3): 221-340.

Lave. J.. \& Wenger, E. (1991). Sinuted learning: Legitimate peripheral participation. Cambridge: Cambridge Liniversity Press.

Lederberg. J.. \& Uncapher. K. (1989). Towards a national collaboratom: Report of an invitational workshop at the Rockefeller Universin: March 17-18. 1989. Paper presented at the meeting of the National Science Foundation Directorate for Computer and Information Science. Washington, DC.

Loh. B.. Rudinsky, J., Russell. E.. Gomez. L.. Reiser. B.. \& Edelson. D. (1998). The Progress Portfolio: Designing retlective tools for a classroom context. Conference on Compurer Human Interaction (CHI) (pp. 627-634). Los Angeles. CA: AC.M. 
McGee, S. (1996), Designing curriculum based on science communities of practice. Unpublished doctoral dissertation. Northwestern Lnitersity. Evanston. IL.

Markus, M.L. (1987). Toward a "critical mass" theory of interactive media: Universal access, interdependence, and diffusion. Communication Research, $14,491-511$.

National Research Council (1996). The national science education standards. Washington, DC: National Academy Press.

Olds. H.F., \& Peurlman, R. (1992). Designing a new American school. Phi Delta Kappan, 74, 296-298.

O'Neill. D.K. (1998). A telementoring initiative to strengthen project-based science leaming. Unpublished doctoral dissertation, Northwestem Lniversity. Evanston, IL.

O'Veill, D.K. \& Gomez, L. (199.1). The Collaboratory Notebook: A distributed knowledgebuilding environment for project-enhanced learning. In T. Ottman, \& I. Tomek (Eds.). Educational multimedia and hypermedia (pp. $+16-123$ ). Charlottesville. VA: Association for the Advancement of Computing in Education.

O Neill. D.K.. Wagner. R.. \& Gomez, L.M. (1996). On-line mentors: Experimenting in science class. Educational Leadership, 54, 39-12.

Pea, R., Gomez. L.. Edelson. D., Fishman. B.. Gordin. D. \& O'Neill. K. (1997). Science education as a driver of cyberspace technology derelopment. In K.C. Cohen (Ed.), Internet links for science education (pp. 189-220). New York: Plenum Press.

Pea. R.. Gomez. L.. Gordin. D.. \& Fishman. B. 1 199-1. K-I and the World Wide Web. Paper presented at the meeting of the Second International World Wide Web Conference. Chicago. IL.

Pea. R.D. (1992). Augmenting the discourse of learning with computer-based learning environments. In E. de Corte. M. Linn. H. Mandl. \& L. Verschaffel (Eds.), Computer-based learning environments and problem-solving (Fo. 313-3+3). New York: Springer-Verlag $\mathrm{GmbH}$.

Pea. R.D. (1993a). Distributed multimedia leaming environments: The Collaborative Visualization Project. Communications of the tC.M $36.60-63$.

Pea. R.D. (1993b). Practices of distributed intelligence and designs for education. In G. Salomon (Ed.). Distributed cognitions: Psycloological and educational considerations (pp. 47-87). New York: Cambridge Lniversity Press.

Pea. R.D. (1994). Seeing what we build together: Distributed multimedia learning environments for transformative communications. The Jouncal of the Learning Sciences, 3. 285-299.

Peil. R.D.. \& Gomez. L.M. (1992). Distributed multimedia learning environments: Why and how? Interactive Learning Enviromments. 2. : $3-109$.

Polman. J., \& Fishman. B. (1995). Acloption of electronic communication tools: Predictors of student success and failure. Paper presented at the meeting of the American Educational Research Association. San Francisco. CA.

Polman. J.. \& Pea. R. (in press). Transformative communication in project science learning discourse. In R. Horowitz (Ed.). The evolution of tulk woout text: Knowing the world through classroom discourse. New York: International Reading Association and Teachers College Press.

Ramamurthy. M.K., \& Kemp. J.G. (1993). Lising the Weacher Machine: A gopher server at the University of Illinois brings weather informution to every desktop. Stom: The World Weather Magazine: 34-39.

Ramamurthy. M.K., Wilhelmson, R.B., Hall. S., Plutchak. J., Sridhar, M., Fishman. B.. Gordin. D.. Pea. R.. \& Gomez, L. (1996). CoVis geosciences web server: An Internet-based 
resource for the K-12 community. Fifth American Merenrological Sociery Symposium on Education (pp. J27-J32). Atlanta. GA: AMS.

Reiser. B.J., Kimberg. D.Y., Lovett. M.C.. \& Ranney, M. (1992). Knowledge representation and explanation in GIL. an intelligent tutor for programming. In J.H. Larkin. \& R.W. Chabay (Eds.), Computer-assisted instruction and intelligent tutoring systems: Shared goals and complementary approaches (pp. 111-149). Hillsdale. .VJ: Lawrence Erlbaum Associates.

Roberts. L. (Ed.) (1988). Poner on!' New tools for teaching and leaming. Washington. DC: US Congress, Office of Technology Assessment.

Ruopp. R.R.. Gal. S.. Drayton. B.. \& Ptister, M. (1993). Lab.Vet: Toward a communiț. of practice. Hillsdale. NJ: Lawrence Eribaum Associares.

Salomon. G. (1991). Transcending the qualitative/quantitative debate: The analytic and systemic approaches to educational research. Edlucational Research. 20. 10-18.

Salomon. G. (1993). Distributed cognitions. New York: Cambridge Liniversity Press.

Scardamalia, M.. Bereiter. C.. McLean. R.S., Swallow, J.. \& Woodruff. E. (1989). Computer supported intentional learning environments. Joumal of Educational Computing Research, 5.51-68.

Shrader. G.. Lento. E.. \& Gomez. L. (1997). Inventing intenentions: Cases from CoVis. Paper presented at the meeting of the American Educational Research Association. Chicago. IL.

Sizer. T. (1988). A visit to an "essential" school. School Administrator: L. $_{18-19 .}$

Songer. ‥B. (1996). Exploring learning opportunities in coordinated network-enhanced classrooms: A case study of Kids As Global Scientists. Joumal of the Learning Sciences, 5 $297-327$.

Tang. J., \& Minneman. S.L. (1991), VideuWhiteBoard: Video shadows to support remote collaboration, $C H I$ '9I (pp. 315-322). New Orleans. LA: Addison Wesley. 